\title{
Prevalence of signs and symptoms of temporomandibular disorders (TMD) in a sample of medical students in Erbil city
}

\begin{abstract}
Dilan Burhan Yousif ${ }^{(1)}$, Zana Qadir Omer ${ }^{(1)}$
Objectives: The aim of the present study was to find the prevalence of temporomandibular disorder by Helkimo anamnesis and clinical dysfunction index and to determine the degree of associations present between temporomandibular disorder and each of age, gender and anxiety.

Methods: 230 students were randomly selected with the age group of 18-25 years, from all colleges of Hawler medical university, from March 2019 to June 2019. Data was collected through Helkimo anamnesis dysfunction index ${ }^{1}$, Helkimo clinical dysfunction index ${ }^{1}$ and generalized anxiety disorder 7-item scale ${ }^{2}$. The data were statistically analyzed by Descriptive statistics and chi square test.

Results: The most encountered symptoms reported by the students were joint sounds (27.4\%) and joint fatigue $(27.4 \%)$. (50\%) of the students had some grade of temporomandibular disorder according to Helkimo anamnesis questionnaire (subjective temporomandibular disorder symptoms) and (57.4\%) had some grade of temporomandibular disorder According to Helkimo clinical dysfunction index (objective temporomandibular disorder symptoms). The associations between temporomandibular disorder and each of age ( $P$-value $=0.900)$, Gender ( $P$ -value $=0.221)$, and anxiety ( $P$-value $=0.288$ ) were statistically not significant by using Helkimo anamnesis questionnaire. Significant association was found between temporomandibular disorder and each of gender (P-value $<0.001)$ and anxiety (P-value $<0.001$ ) by using Helkimo clinical dysfunction index.

Conclusion: In conclusion, the prevalence of temporomandibular disorder was high. The most common symptom reported by students were joint sounds and joint fatigue. According to Helkimo clinical dysfunction index temporomandibular disorder was more prevalent among females and those who had a degree of anxiety.
\end{abstract}

Keywords: College students, anxiety, Helkimo index

\footnotetext{
${ }^{(1)}$ College of Dentistry, Hawler Medical University, Erbil, Iraq.

Tel: 07503703717

Email: dilanburhan9@gmail.com
}

\section{Introduction}

Temporomandibular disorders (TMD) are a number of conditions that interfere with the normal function of the temporomandibular joint and related structures $^{3}$, causing signs and symptoms like pain, limitation of mouth opening and temporomandibular joint sounds. ${ }^{4}$ Usually, the patient seek treatment when the significant symptoms arise however in many cases TMD can exist with sub clinical symptoms. ${ }^{5}$ A number of factors are associated with TMD and those factors are either dental, medical or mental, some of these factors include parafunctional habits, trauma, muscle pathophysiology and emotional stress. Age and gender are two other factors that has been studied but it has not proved whether they are causative factors or just concurrent factors. ${ }^{4}$ There are some factors that put college students under the risk of developing TMD among them are study associated stress ${ }^{6}$, study associated parafunction $^{7}$ and unfavorable body position while studying or lab working ${ }^{8}$.

According to Liu and Steinkeler ${ }^{9}$ college 
students are at higher risk of TMD because of their age since the peak age of starting TMD symptoms is 20 years.

The prevalence of TMD was estimated by a population based study done by Isong et al to be between $8 \%$ to $15 \%$ for females and $3 \%$ to $10 \%$ for males. ${ }^{10}$ TMD prevalence differs from male to female, different age groups, races and socioeconomic status. ${ }^{10,11}$ For the purpose of measuring TMD there is an absolute need of dependable and relatively simple indices. Among those commonly used indices were anamnestic index and clinical dysfunction index proposed by Helkimo in 1974. ${ }^{1}$ There are several studies published concerning the prevalence of TMD in other countries abroad. ${ }^{12-23}$ According to the researchers knowledge there is no study done in Erbil city about TMD prevalence, therefore the objective of the present study is to determine the prevalence of TMD in Hawler medical university and to find out the associations between TMD and each of age, gender and anxiety.

\section{Methods}

A total number of 230 students were randomly selected with the age group of 18-25 years, from all colleges of Hawler medical university, namely, college of medicine, college of dentistry, college of pharmacy, college of nursing, and college of health sciences, from March 2019 to June 2019. Data was collected through Helkimo anamnesis dysfunction index ${ }^{1}$, Helkimo clinical dysfunction index ${ }^{1}$ and generalized anxiety disorder 7-item scale (GAD-7) ${ }^{2}$. Patients with all permanent dentition were included in the study. Patients with clinically diagnosed TMD with treatment were excluded from the study.

The Helkimo anamnesis dysfunction questionnaire is composed of 8 questions with yes and no answers, proposed by Marti Helkimo for evaluation of TMD. The criteria and scoring were all described in detail by Helkimo. ${ }^{1}$ The anamnestic questionnaire was translated in to Kurdish language and questions were asked in Kurdish to accomplish repeatability and consistency in asking by the researcher. The Helkimo clinical dysfunction index was proposed by Marti Helkimo to know the severity of TMD by examining the subjects for 5 symptoms and each symptom had three grades using 0,1 or 5 points. The five symptoms were: impaired range of movement of the mandible, impaired function of the temporomandibular joint, pain on movement of the mandible, muscle pain and temporomandibular joint pain, their criteria and scoring were all described in detail by Helkimo. ${ }^{1}$ The level of anxiety was measured by Generalized Anxiety Disorder 7-item (GAD-7) scale. The scale is composed of 7 signs and symptoms felt by the patient in the past 2 weeks, ${ }^{2}$ including the repetition of the signs in the days of the week. The scoring were all described in detail by Spitzer et al.

Statistical analysis. The data was submitted to chi square test to show the strength of association between the prevalence of temporomandibular joint disorder, age, gender, and anxiety disorder, using SPSS software package (Version 23). The level of significance was set at $\mathrm{p}<0.05$.

\section{Results}

The response rate was $92 \%$ because $8 \%$ of the students either did not proceed with the interview or they refused to be examined by the researcher, so were not included in the study. Descriptive analysis showed that the mean \pm standard deviation of the age of the students who participated was $(20.2870 \pm$ 1.79648). (Figure 1) shows that most of the students who participated in the study were females (63\%). According to (Figure 2), the students were composed mostly of 19-21 age group $(63 \%)$.

It's evident from (Table 1) that the most encountered symptoms reported by the students were joint sounds $(27.4 \%)$ and joint fatigue (27.4\%). (Table 2) shows that $(50 \%)$ of the students had some grade of TMD and nearly one fourth of them had severe symptoms according to Helkimo anamnesis questionnaire (subjective TMD symptoms). The sample included 98 students $(42.6 \%)$ free from TMD symptoms while the rest $(57.4 \%)$ had TMD symptoms and they were either mild, moderate or 
severe symptoms According to Helkimo clinical dysfunction index (objective TMD symptoms) as its shown in (Table 3 ).

The associations between TMD and each of age $(\mathrm{P}$-value $=0.900)$, Gender $(\mathrm{P}$-value $=$ 0.221 ), and GAD (P-value $=0.288$ ) were statistically not significant by using Helkimo anamnesis questionnaire as seen in each of (Table 4), (Table 5) and (Table 6) respectively. Similarly the association between TMD and age by using Helkimo clinical dysfunction index $(\mathrm{P}$-value $=0.357)$ was not significant either (Table 7). On contrary there was a highly significant association between TMD and genderusing
Helkimo clinical dysfunction index (P-value $<0.001)$ as it's evident

in (Table 8) that moderate $(20 \%)$ and severe $(2.2 \%)$ TMD in females was significantly higher than moderate $(3.5 \%)$ and severe $(0.4 \%)$ TMD in males. Another highly significant association (P-value $<0.001$ ) was present between TMD and GAD using Helkimo clinical dysfunction index. It's clearly evident from (Table 9) that symptom free TMD was higher among those with minimal GAD (26.5\%) and lower among mild $(13 \%)$, moderate $(2.6 \%)$ and severe GAD $(0.4 \%)$.

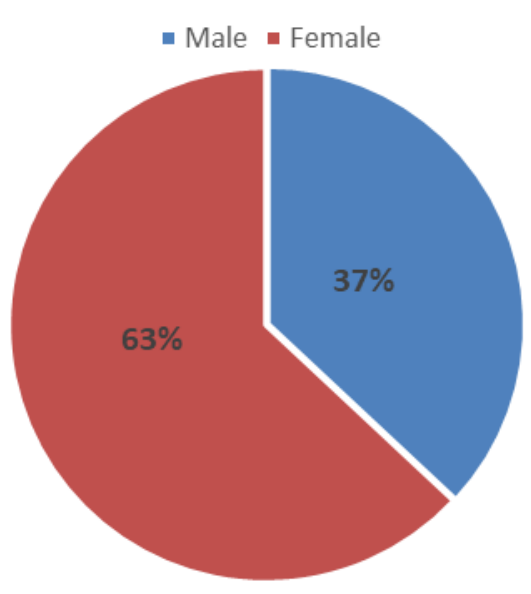

Figure 1: A-Pie chart of gender distribution of the sample.gender distribution of the sample.

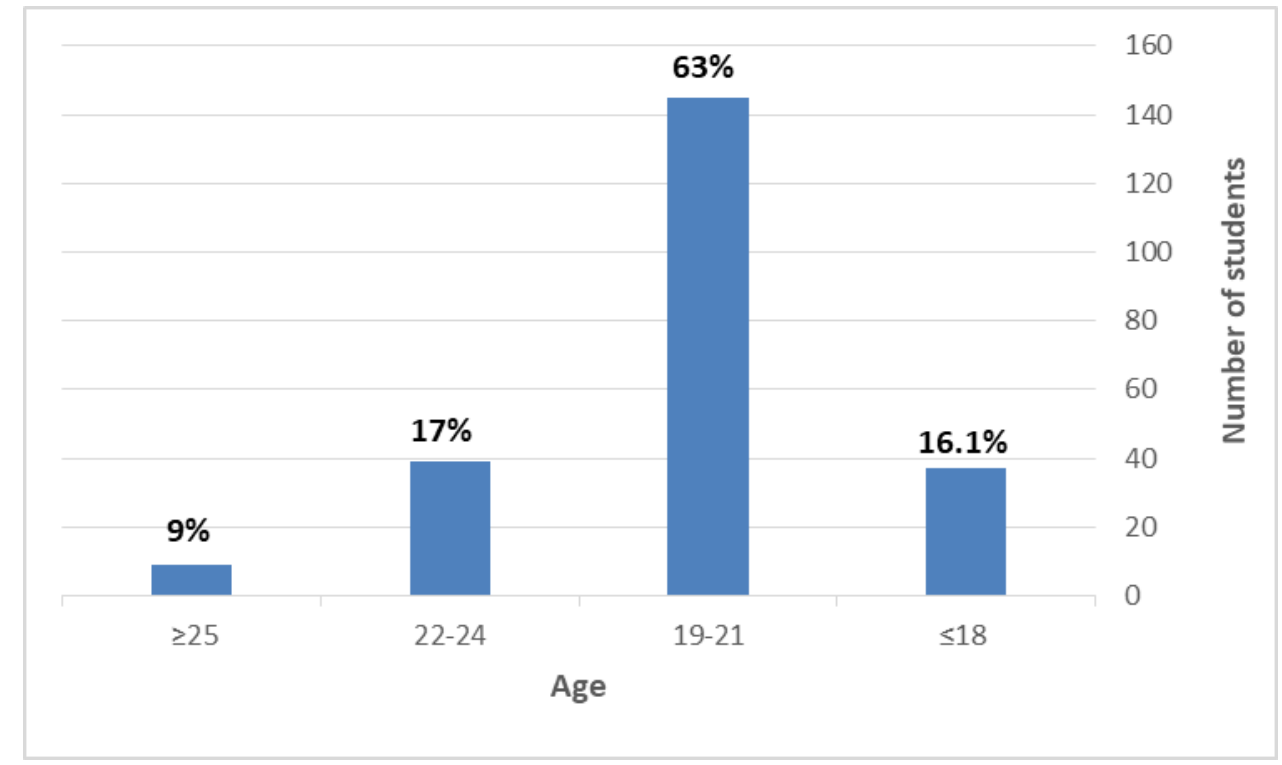

Figure 2: Bar-chart of age Distribution of the sample. 
Table 1: Frequency of TMD symptoms according to .Helkimo anamnesis questionnaire.

\begin{tabular}{|c|c|c|c|}
\hline & $\begin{array}{c}\text { Frequency of Symptoms according to Helkimo anamne- } \\
\text { sis questionnaire }\end{array}$ & No. & Percentage\% \\
\hline 1 & Sound in the TMJ area & 34 & $27.4 \%$ \\
\hline 2 & Jaw rigidity & 63 & $27.4 \%$ \\
\hline 3 & Fatigue in the jaw area & 19 & $8.3 \%$ \\
\hline $\mathbf{4}$ & Difficulty when opening the mouth & 22 & $9.6 \%$ \\
\hline $\mathbf{5}$ & Locked mandible & 35 & $15.2 \%$ \\
\hline $\mathbf{6}$ & Pain in the TMJ or in the area of masticatory muscles & 14 & $6.1 \%$ \\
\hline $\mathbf{7}$ & Pain during mandible movement & & $6.1 \%$ \\
\hline
\end{tabular}

Table 2: prevalence of TMD levels by using Helkimo anamnesis Helkimo anamnesis questionnaire index.

\begin{tabular}{|c|c|c|}
\hline $\begin{array}{c}\text { Severity of TMD according to Helkimo } \\
\text { anamnesis index }\end{array}$ & No. & Percentage \% \\
\hline Symptom free (Ai-0) & 115 & $50 \%$ \\
\hline Mild (Ai-I) & 55 & $23.9 \%$ \\
\hline Severe (Ai-I) & 60 & $26.1 \%$ \\
\hline Total & 230 & $100 \%$ \\
\hline
\end{tabular}

Table 3: Prevalence of TMD levels by using Helkimo clinical dysfunction index

\begin{tabular}{|c|c|c|}
\hline $\begin{array}{c}\text { Severity of TMD according to } \\
\text { Helkimo clinical dysfunction index }\end{array}$ & No. & Percentage \% \\
\hline Symptomfree (Di-0) & 98 & $42.6 \%$ \\
\hline Mild (Di-I) & 72 & $31.3 \%$ \\
\hline Moderate (Di-II) & 54 & $23.5 \%$ \\
\hline Severe (Di-III) & 6 & $2.6 \%$ \\
\hline Total & 230 & $100 \%$ \\
\hline
\end{tabular}


Table 4: Association between Age and TMD by using Helkimo anamnesis questionnaire index.

\begin{tabular}{|c|c|c|c|c|c|c|c|c|c|}
\hline \multirow{3}{*}{ Age } & \multicolumn{8}{|c|}{ TMD severity according to Helkimo anamnesis index } & \multirow{3}{*}{ P-value } \\
\hline & \multicolumn{2}{|c|}{ symptom free } & \multicolumn{2}{|c|}{ Mild } & \multicolumn{2}{|c|}{ Severe } & \multicolumn{2}{|c|}{ Total } & \\
\hline & No. & $\%$ & No. & $\%$ & No. & $\%$ & No. & $\%$ & \\
\hline$\leq 18$ & 17 & $7.4 \%$ & 12 & $5.2 \%$ & 8 & $3.5 \%$ & 37 & $16.1 \%$ & \\
\hline $19-21$ & 73 & $31.7 \%$ & 33 & $14.3 \%$ & 39 & $17 \%$ & 145 & $63 \%$ & \\
\hline $22-24$ & 21 & $9.1 \%$ & 8 & $3.5 \%$ & 10 & $4.3 \%$ & 39 & $17 \%$ & 0.900 \\
\hline$\geq 25$ & 4 & $1.7 \%$ & 2 & $0.9 \%$ & 3 & $1.3 \%$ & 9 & $3.9 \%$ & \\
\hline Total & 115 & $50 \%$ & 55 & $23.9 \%$ & 60 & $26.1 \%$ & 230 & $100 \%$ & \\
\hline
\end{tabular}

Table 5: Association between Gender and TMD by using Helkimo anamnesis questionnaire index.

\begin{tabular}{|c|c|c|c|c|c|c|c|c|c|}
\hline \multirow{3}{*}{ Gender } & \multicolumn{8}{|c|}{ TMD severity according to Helkimo anamnesis index } & \multirow{3}{*}{$\begin{array}{c}\mathrm{P} \text { - } \\
\text { value }\end{array}$} \\
\hline & \multicolumn{2}{|c|}{ symptom free } & \multicolumn{2}{|c|}{ Mild } & \multicolumn{2}{|c|}{ Severe } & \multicolumn{2}{|c|}{ Total } & \\
\hline & No. & $\%$ & No. & $\%$ & No. & $\%$ & No. & $\%$ & \\
\hline Male & 47 & $20.4 \%$ & 15 & $6.5 \%$ & 23 & $105 \%$ & 85 & $37 \%$ & \\
\hline Female & 68 & $29.6 \%$ & 40 & $17.4 \%$ & 37 & $16.1 \%$ & 145 & $63 \%$ & \\
\hline Total & 115 & $50 \%$ & 55 & $23.9 \%$ & 60 & $26.1 \%$ & 230 & $100 \%$ & \\
\hline
\end{tabular}

Table 6: Association between anxiety and TMD by using Helkimo anamnesis questionnaire index and GAD

\begin{tabular}{|c|c|c|c|c|c|c|c|c|c|}
\hline \multirow{2}{*}{$\begin{array}{c}\text { Severity of } \\
\text { anxiety } \\
\text { according } \\
\text { to GAD 7- } \\
\text { item scale } \\
\text { index }\end{array}$} & \multicolumn{6}{|c|}{ TMD severity according to Helkimo anamnesis index } & \multicolumn{2}{c|}{ Total } & $\begin{array}{c}\text { P- } \\
\text { value }\end{array}$ \\
\cline { 2 - 10 } & No. & $\%$ & No. & $\%$ & No. & $\%$ & No. & $\%$ & \\
\hline Minimal & 54 & $23.5 \%$ & 21 & $9.1 \%$ & 25 & $10.9 \%$ & 100 & $43.5 \%$ & \\
\hline Mild & 32 & $13.9 \%$ & 19 & $8.3 \%$ & 11 & $4.8 \%$ & 62 & $27 \%$ & \\
\hline Moderate & 18 & $7.8 \%$ & 8 & $3.5 \%$ & 16 & $7 \%$ & 42 & $18.3 \%$ & 0.288 \\
\hline Severe & 11 & $4.8 \%$ & 7 & $3 \%$ & 8 & $3.5 \%$ & 26 & $11.3 \%$ & \\
\hline Total & 115 & $50 \%$ & 55 & $23.9 \%$ & 60 & $26.1 \%$ & 230 & $100 \%$ & \\
\hline
\end{tabular}


Table 7: Association between Age and TMD by using Helkimo clinical dysfunction index.

\begin{tabular}{|c|c|c|c|c|c|c|c|c|c|c|c|}
\hline \multirow{3}{*}{ Age } & \multicolumn{10}{|c|}{ TMD severity according to Helkimo clinical dysfunction index } & \multirow{3}{*}{$\begin{array}{c}\text { P- } \\
\text { value }\end{array}$} \\
\hline & \multicolumn{2}{|c|}{ Symptom free } & \multicolumn{2}{|c|}{ Mild } & \multicolumn{2}{|c|}{ Moderate } & \multicolumn{2}{|c|}{ Severe } & \multicolumn{2}{|c|}{ Total } & \\
\hline & No. & $\%$ & No. & $\%$ & No. & $\%$ & No. & $\%$ & No. & $\%$ & \\
\hline$\leq 18$ & 20 & $8.7 \%$ & 7 & $3 \%$ & 10 & $4.3 \%$ & 0 & $0 \%$ & 37 & $16.1 \%$ & \multirow{5}{*}{0.357} \\
\hline 19-21 & 59 & $25.7 \%$ & 48 & $20.9 \%$ & 32 & $13.9 \%$ & 6 & $2.6 \%$ & 145 & $63 \%$ & \\
\hline $22-24$ & 16 & $7 \%$ & 12 & $5.2 \%$ & 11 & $4.8 \%$ & 0 & $0 \%$ & 39 & $17 \%$ & \\
\hline$\geq 25$ & 3 & $1.3 \%$ & 5 & $2.2 \%$ & 1 & $0.4 \%$ & 0 & $0 \%$ & 9 & $3.9 \%$ & \\
\hline Total & 98 & $42.6 \%$ & 72 & $31.3 \%$ & 54 & $23.5 \%$ & 6 & $2.6 \%$ & 230 & $100 \%$ & \\
\hline
\end{tabular}

Table 8: Association between Gender and TMD by using Helkimo clinical dysfunction index.

\begin{tabular}{|c|c|c|c|c|c|c|c|c|c|c|c|}
\hline \multirow{3}{*}{ Gender } & \multicolumn{10}{|c|}{ TMD severity according to Helkimo clinical dysfunction index } & \multirow{3}{*}{ P-value } \\
\hline & \multicolumn{2}{|c|}{ symptomfree } & \multicolumn{2}{|c|}{ Mild } & \multicolumn{2}{|c|}{ Moderate } & \multicolumn{2}{|c|}{ Severe } & \multicolumn{2}{|c|}{ Total } & \\
\hline & No. & $\%$ & No. & $\%$ & No. & $\%$ & No. & $\%$ & No. & $\%$ & \\
\hline Male & 47 & $20.4 \%$ & 29 & $12.6 \%$ & 8 & $3.5 \%$ & 1 & $0.4 \%$ & 85 & $37 \%$ & \multirow{3}{*}{$<0.001$} \\
\hline Female & 51 & $22.2 \%$ & 43 & $18.7 \%$ & 46 & $20 \%$ & 5 & $2.2 \%$ & 145 & $63 \%$ & \\
\hline Total & 98 & $42.6 \%$ & 72 & $31.3 \%$ & 54 & $23.5 \%$ & 6 & $2.6 \%$ & 230 & 100 & \\
\hline
\end{tabular}

Table 9: Association between anxiety and TMD by using Helkimo clinical dysfunction index and GAD 7-item scale.

\begin{tabular}{|c|c|c|c|c|c|c|c|c|c|c|c|}
\hline \multirow{3}{*}{$\begin{array}{c}\text { Severity of } \\
\text { anxiety accord- } \\
\text { ing to GAD 7- } \\
\text { item scale } \\
\text { index }\end{array}$} & \multicolumn{10}{|c|}{ TMD severity according to Helkimo clinical dysfunction index } & \multirow{3}{*}{$\begin{array}{c}\text { P- } \\
\text { value }\end{array}$} \\
\hline & \multicolumn{2}{|c|}{ symptomfree } & \multicolumn{2}{|c|}{ Mild } & \multicolumn{2}{|c|}{ Moderate } & \multicolumn{2}{|c|}{ Severe } & \multicolumn{2}{|c|}{ Total } & \\
\hline & No. & $\%$ & No. & $\%$ & No. & $\%$ & No. & $\%$ & No. & $\%$ & \\
\hline Minimal & 61 & $26.5 \%$ & 32 & $13.9 \%$ & 5 & $2.2 \%$ & 2 & $0.9 \%$ & 100 & $43.5 \%$ & \\
\hline Mild & 30 & $13 \%$ & 26 & $11.3 \%$ & 5 & $2.2 \%$ & 1 & $0.4 \%$ & 62 & $27 \%$ & \\
\hline Moderate & 6 & $2.6 \%$ & 7 & $3 \%$ & 27 & $11.7 \%$ & 2 & $0.9 \%$ & 42 & $18.3 \%$ & $<0.001$ \\
\hline Severe & 1 & $0.4 \%$ & 7 & $3 \%$ & 17 & $7.4 \%$ & 1 & $0.4 \%$ & 26 & $11.3 \%$ & \\
\hline Total & 98 & $42.6 \%$ & 72 & $31.3 \%$ & 54 & $23.5 \%$ & 6 & $2.6 \%$ & 230 & $100 \%$ & \\
\hline
\end{tabular}




\section{Discussion}

The present study has provided information about the students at Hawler Medical University in Erbil, Iraq on the prevalence of TMD and its relation with age, gender and anxiety by using anamnestic questionnaire of Helkimo and Helkimo clinical dysfunction index ${ }^{1}$. The decision to use the Helkimo anamnesis and dysfunction index together in this study, was based on the possibility of subjectively and objectively measuring the severity of TMD, because according to Helkimo the anamnesis questionnaire only takes the subjects' symptoms while the clinical dysfunction index measures the degree of TMD present by taking in to account the severity of the TMD signs examined by the researcher and both indices has their own scoring. There were difference between subjective and objective TMD prevalence in this study and that's probably because there is no significant association between these two indices as concluded by Ajanovic and Bejtovic $^{24}$.In this study the prevalence of subjective TMD (50\%) was less than the objective one $(57.4 \%)$ since TMD can occur with no subjective symptoms. ${ }^{5}$

The effect of anxiety on pain threshold on muscles of mastication has been found and mentioned by both Nomura et $\mathrm{al}^{25}$ and Okeson $^{26}$, And it has also been found that the level of anxiety and stress among college students during college years are relatively high and this is due to the importance of these years for their future professions. ${ }^{27}$ so choosing young college students as subjects in this study has been decided because they are considered as risk groups for anxiety and stress. The most encountered symptoms reported by the students were joint sounds and joint fatigue which was in accordance with many studies that found clicking to be the most encountered symptom. ${ }^{28,29}$ however in a study done by Bagis et $\mathrm{al}^{21} 92 \%$ of the participants had temporal muscle pain as the most frequent symptom. Other studies found that poor articulation of teeth ${ }^{30}$, mandibular deviation $^{23}$ and Headache ${ }^{14}$ were the most occurring symptom

In this study the prevalence of subjective TMD (measured by using Helkimo anamnesis questionnaire) were $50 \%$ which was in exact accordance to a study by Bonjardim et $\mathrm{al}^{31}$, however the results of Aldridge and Fenlon ${ }^{32}$, and Al-Hayek et $\mathrm{al}^{16}$, showed lower prevalence rate and a study done in Brazil by Bezerra et $\mathrm{al}^{33}$ along with another study by Aldhalai et $\mathrm{al}^{30}$ in saudi arabia had found higher prevalence rate. The prevalence of objective TMD (measured by using Helkimo clinical dysfunction index) was $57.4 \%$ which was nearly the same as a study by Boscato et $\mathrm{al}^{34}$ and less than what was found by (Al-Hayek et $\mathrm{al}^{16}$, Alhussini et $\mathrm{al}^{14}$, and Ahmed and Abuaffan $^{28}$, and lower results had been found by Calderón et $\mathrm{al}^{23}$ and Al-khotani et $\mathrm{al}^{35}$. Lower prevalence of objective TMD in this study was probably because the presence of all permanent tooth was an inclusion criteria and according to Gesch et $\mathrm{al}^{36}$ the number of teeth in occlusion is a protective factor for TMD This study's results revealed that age, gender or anxiety had no significant association with subjective TMD, the same findings were reported about age and gender by Akhter et $\mathrm{al}^{37}$ a study done among 1930 university students by using interview questionnaires in japan. Current study's results disagreed with a study done by Bezerra et $\mathrm{al}^{33}$ that showed significant association between gender and subjective TMD in which females were predominant, and the same study $^{33}$ found that subjective TMD and stress were significantly associated. Aldhalai et $\mathrm{l}^{30}$ had studied subjective TMD among 318 participants in Saudi Arabia using Fonesca questionnaire concluding that there was no difference between genders, while the severity of subjective TMD increases with increasing age. Opposed to this study's results Bonjardim et $\mathrm{al}^{31}$ had found a significant association between subjective TMD and anxiety. Females had more severe objective TMD than males in this study, the same findings had been reported by Adèrn et $\mathrm{al}^{38}$, Bagis et $\mathrm{al}^{21}$, Boscato et $\mathrm{al}^{34}$, Aldridge and Fenlon ${ }^{32}$, and Al-Hayek et $\mathrm{al}^{16}$. On the other hand other studies $^{14,23,29,}$ showed no significant difference between both genders.

The reason that TMD is more prevalent in females than males is probably because of physiological differences between females and males such as: hormonal variations, 
lower pain threshold. ${ }^{39}$ And this fact clarifies that why the peak prevalence of TMD in females is during reproductive years and women using estrogen as supplement or oral contraceptives tend to seek TMD treatment more. ${ }^{40}$ It was found that there was no significant association between age and objective TMD in this study which was in agreement with Boscato et $\mathrm{al}^{34}$ and Alhussini et $\mathrm{al}^{14}$. And that is probably because of minimum differences between the age groups of our sample. Students with GAD in the present study showed more objective TMD compared with those who don't have GAD, which is in accordance with what was found by Boscato et $\mathrm{al}^{34}$ with $(\mathrm{P}$-value $=0.001)$. It's important to mention that the time of this study was concurrent with students exam time and that affected their level of stress and anxiety. In a study ${ }^{41}$ in Mexico by using both questionnaire and clinical examination $46.1 \%$ of the participants had some grade of TMD and it was concluded that gender, stress and anxiety to be the most significant associated factors. In general there was a huge diversity of TMD prevalence among studies done worldwide. The reasons were: the sample's age group, the diagnostic methods used and the type of the population studied. ${ }^{42}$

\section{Conclusion}

Based on the result of this study, the prevalence of TMD measured by both Helkimo questionnaire and Helkimo clinical dysfunction index were high. However the severe TMD cases by using both indices were relatively low. The most common symptom reported by students were joint sounds and joint fatigue. Additionally no statistically significant association were found between TMD and each of age, gender and anxiety by using Helkimo anamnesis questionnaire, however the association between TMD and each of gender and anxiety were very significant by using helkimo clinical dysfunction index.

\section{Conflict of interest}

The authors reported no conflict of interests.

\section{References}

1. Helkimo M. Studies on function and dysfunction of the masticatory system II. Index for anamnestic and clinical dysfunction and occlusal state. Swed. Dent. J. 1974. 67(2): 101-21

2. Spitzer RL, Kroenke K, Williams JBW, Lowe B. A brief measure for assessing generalized anxiety disorder. Arch Inern Med 2006; 166(10):1092-7.

3.Al-Ani Z, Gray R. TMD Current Concepts: 1. An Update. Dental Update 2007;34(5):278-88.

4. Cooper BC, Kleinberg I. Examination of a Large Patient Population for the Presence of Symptoms and Signs of Temporomandibular Disorders. Cranio ${ }^{\circledR}$ 2007;25(2):114-26.

5. Okeson JP. Management of Temporomandibular Disorders and Occlusion. 7th ed. St. Louis, MO: Elsevier/Mosby; 2013.

6. Stallman HM. Psychological distress in university students: A comparison with general population data. Australian Psychologist 2010;45(4):249-57.

7. Grzywacz R., "Overview of the stress in the student group on the basis of own research," Medycyna Rodzinna, vol. 62, no. 2, pp. 36-43, 2012

8. Abou-Atme Y. S., M. Melis, K. H. Zawawi, and L. Cottogno. Five-year follow-up of temporomandibular disorders and other musculoskeletal symptoms in dental students. Minerva stomatologica 2007;56(11-12): 603-9.

9. Liu F. and A. Steinkeler. Epidemiology, diagnosis, and treatment of temporomandibular disorders. Dental Clinics of North America 2013; 57(3): 46579.

10.Isong U, Gansky SA, Plesh O. Temporomandibular joint and muscle disorder-type pain in U.S. adults: the National Health Interview Survey. Journal of orofacial pain. 2008; 22(4):317-22.

11.Janal MN, Raphael KG, Nayak S, Klausner J. Prevalence of myofascial temporomandibular disorder in US community women. Journal of oral rehabilitation. 2008; 35(11):801-9.

12. Rani S, Pawah S, Gola S, Bakshi M. Analysis of Helkimo index for temporomandibular disorder diagnosis in the dental students of Faridabad city: A cross-sectional study. The Journal of Indian Prosthodontic Society 2017; 17(1): 48-52.

13. Moaleem MM, Okshah AMS, Al-Shahrani AA, Alshadidi AKAF, Shaabi FI, Mobark AH, et al. Prevalence and Severity of Temporomandibular Disorders among Undergraduate Medical Students in Association with Khat Chewing. J Contemp Dent Pract 2017;18(1):1-6.

14. Alhussini D. Prevalence and Awareness of Temporomandibular Joint Disorders among Patients in King Abdulaziz University, Dental Hospital. Journal of Dental Health, Oral Disorders \& Therapy 2017; 
8(5): 1-6.

15. Al-Gadhaan SM, Khan P, Alqahtani S, Alsahrani B, Alqahtani B. Prevalence of TMJ disorders among the general population in southern region of kingdom of Saudi Arabia- a survey report from dental center of Afhsr. Med. Res. Chron. 2018; 5 (1): 36-42

16.Al Hayek S, Al-Thunayan M, AlGhaihab A, AlReshaid R, Omair A. Assessing stress associated with temporomandibular joint disorder through Fonseca's an: 1-7. amnestic index among the Saudi physicians. Clinical and Experimental Dental Research 2018

17. Paduano S, Bucci R, Rongo R, Silva R, Michelotti A. Prevalence of temporomandibular disorders and oral parafunctions in adolescents from public schools in Southern Italy. Cranio ${ }^{\circledR}$. 2018:1-6.

18. Elyasi M, Majeed S, Elyassi M, Aziz A, Rashid K, Ali $S$, et al. Prevalence of temporomandibular joint disorder among Gulf Medical University students. Gulf Medical Journal 2016;5(S1):S123-S130.

19. Olivares H, Saucedo F, Nova A. Temporomandibular joint disorder prevalence in resident physicians at the Specialties Hospital "La Raza» National Medical Center. Revista Odontológica Mexicana 2016; 20(1): e8-e12.

20. Bilgiç F, Gelgör i. Prevalence of Temporomandibular Dysfunction and its Association with Malocclusion in Children: An Epidemiologic Study. Journal of Clinical Pediatric Dentistry 2017; 41(2): 1615.

21. Bagis B, Ayaz E, Turgut S, Durkan R, Özcan M. Gender Difference in Prevalence of Signs and Symptoms of Temporomandibular Joint Disorders: A Retrospective Study on 243 Consecutive Patients. International Journal of Medical Sciences 2012; 9(7): 539-44.

22. Yu Q, Liu Y, Chen $X$, Chen $D$, Xie L, Hong $X$, et al. Prevalence and associated factors for temporomandibular disorders in Chinese civilian pilots. International Archives of Occupational and Environmental Health 2015; 88(7): 905-11.

23. Calderón $\mathrm{CL}$, Layera LS, Núñez CV, Perez NS. Prevalence of signs and symptoms of temporomandibular disorders before orthodontic treatment in a population of Santiago, Chile. Rev. Clin. Periodoncia Implantol. Rehabil. Oral 2018; 11(3): 160-3.

24.Ajanovic M, Bejtovic B. Correlation Between Values of the Helkimo Anamnestic and Clinical Dysfunction Index in Patients Suffering from Post Traumatic Stress Disorder. Mater Sociomed 2009; 21(2): 85-91.

25. Nomura K, Vitri M, Oliveira AS, et al. Use the Fonseca's questionnaire to assess the prevalence and severity of temporomandibular disorders in brazilian dental undergraduates. Braz Dent J. 2007;18(2):163-7.

26. Okeson JP. Joint intracapsular disorders: diagnostic and nonsurgical management considerations. Dent Clin North. 2007;51(1):85-103.

27. Pedroni CR, Oliveira SD, Guaratini MI. Prevalence study of temporomandibular disorders in university students. J Oral Rehabil. 2003;30 (3):283-9

28. Ahmed LI, Abuaffan AH. Prevalence of Temporomandibular Joint Disorders among Sudanese University Students. J Oral Hyg Health 2016; 4(2): 1-5.

29. Bonjardim LR, Gavião MB, Pereira LJ, Castelo PM, Garcia RC. Signs and symptoms of temporomandibular disorders in adolescents. Brazilian Oral Research 2005; 19(2):93-8.

30. Aldhalai MA, Alyami YAS, Al Haider YMB, Aldhili MK, Alyami DAS, Alyami SAS, et al. Prevalence and Severity of Temporomandibular Joint Disorders among Populations in Najran Province, Kingdom of Saudi Arabia. World J Dent 2017;8(2):905.

31. Bonjardim LR, Lopes-Filho RJ, Amado G, Albuquerque RL, Goncalves SR. Association between symptoms of temporomandibular disorders and gender, morphological occlusion, and psychological factors in a group of university students. Indian J Dent Res 2009;20(2):190-4.

32. Aldridge RD, Fenlon MR. Prevalence of temporomandibular dysfunction in a group of scuba divers. Br J Sports Med 2004;38(1):69-73.

33. Bezerra B, Ribeiro A, Farias A, Farias A, Fontes L, Nascimento $S$, et al. Prevalence of temporomandibular joint dysfunction and different levels of anxiety among college students. Rev Dor. São Paulo 2012;13(3):235-42.

34. Boscato N, Almeida RC, Koller CD, Presta AA, Goettems ML. Influence of anxiety on temporomandibular disorders - an epidemiological survey with elders and adults in Southern Brazil. Journal of Oral Rehabilitation 2013 40(9); 643-49.

35. Al-Khotani A, Naimi-Akbar A, Albadawi E, Ernberg $M$, Hedenberg-Magnusson B, Christidis N. Prevalence of diagnosed temporomandibular disorders among Saudi Arabian children and adolescents. The Journal of Headache and Pain 2016; 17: 41

36. Gesch D, Bernhardt O, Alte D, Schwahn C, Kocher $T$, John $U$ et al. Prevalence of signs and symptoms of temporomandibular disorders in an urban and rural German population: results of a population-based study of health in Pomerania. Quintessence Int. 2004;35(2):143-50.

37Akhter R, Morita M, Ekuni D, Hassan NM, Furuta $M$, Yamanaka $R$, et al. Self-reported aural symp- 
toms, headache and temporomandibular disorders in Japanese young adults. BMC Musculoskeletal Disorders. 2013;14(1): 1-7

38. Adèrn B, Stenvinkel C, Sahlqvist L, Tegelberg Å. Prevalence of temporomandibular dysfunction and pain in adult general practice patients. Acta Odontologica Scandinavica 2014; 72(8): 585-90.

39. Vedolin GM, Lobato VV, Conti PC, Lauris JR. The impact of stress and anxiety on the pressure pain threshold of myofascial pain patients. J Oral Rehabil. 2009;36(5):313-21

40. Lora VR, Canales Gde L, Gonçalves LM, Meloto $\mathrm{CB}$, Barbosa CM. Prevalence of temporomandibular disorders in postmenopausal women and rela- tionship with pain and HRT. Braz Oral Res. 2016; 30(1): e100.

41. Casanova-Rosado JF, Medina-Solís CE, VallejosSánchez AA, Casanova-Rosado AJ, HernándezPrado B, Ávila-Burgos L. Prevalence and associated factors for temporomandibular disorders in a group of Mexican adolescents and youth adults. Clin Oral Invest. 2005;10(1):42-9.

42. Agarwal K, Saha S, Sinha P. Prevalence of temporomandibular disorders and its association with parafunctional habits among senior-secondary school children of Lucknow, India. J Indian Assoc Public Health Dent 2016;14(2):139-43. 